University of Nebraska - Lincoln

DigitalCommons@University of Nebraska - Lincoln

\title{
Dispersal of Boll Weevils (Coleoptera: Curculionidae) from Cotton Modules Before Ginning
}

Thomas W. Sappington

USDA-ARS, tsapping@iastate.edu

Mark D. Arnold

Texas A\&M University

Alan D. Brashears

USDA-ARS-CPPRU

Megha N. Parajulee

Texas A\&M University

Stanley C. Carroll

Texas A\&M University

See next page for additional authors

Follow this and additional works at: https://digitalcommons.unl.edu/usdaarsfacpub

Part of the Agricultural Science Commons

Sappington, Thomas W.; Arnold, Mark D.; Brashears, Alan D.; Parajulee, Megha N.; Carroll, Stanley C.; Knutson, Allen E.; and Norman, John W. Jr., "Dispersal of Boll Weevils (Coleoptera: Curculionidae) from Cotton Modules Before Ginning" (2006). Publications from USDA-ARS / UNL Faculty. 731.

https://digitalcommons.unl.edu/usdaarsfacpub/731

This Article is brought to you for free and open access by the U.S. Department of Agriculture: Agricultural Research Service, Lincoln, Nebraska at DigitalCommons@University of Nebraska - Lincoln. It has been accepted for inclusion in Publications from USDA-ARS / UNL Faculty by an authorized administrator of DigitalCommons@University of Nebraska - Lincoln. 


\section{Authors}

Thomas W. Sappington, Mark D. Arnold, Alan D. Brashears, Megha N. Parajulee, Stanley C. Carroll, Allen E. Knutson, and John W. Norman Jr. 


\title{
Dispersal of Boll Weevils (Coleoptera: Curculionidae) from Cotton Modules Before Ginning
}

\author{
THOMAS W. SAPPINGTON,${ }^{1}$ MARK D. ARNOLD, ${ }^{2}$ ALAN D. BRASHEARS,${ }^{3}$ \\ MEGHA N. PARAJULEE, ${ }^{2}$ STANLEY C. CARROLL, ${ }^{2}$ ALLEN E. KNUTSON, ${ }^{4}$ \\ AND JOHN W. NORMAN, JR. ${ }^{5}$
}

USDA-ARS, Corn Insect and Crop Genetics Research Unit, Genetics Laboratory, Iowa State University, Ames, IA 50011

\section{J. Econ. Entomol. 99(1): 67-75 (2006)}

\begin{abstract}
We characterized the level of risk of boll weevil, Anthonomus grandis grandis Boheman, reintroduction to an eradication zone posed by dispersal from cotton modules during and after transport to the gin. Mark-release-recapture experiments in August and September in Texas indicated that most weevils disperse rapidly from the module surface, temperature permitting, unless confined under a module tarp, where most died. Nevertheless, 1-5\% of released weevils were recovered alive after $24 \mathrm{~h}$ on the side and top surfaces of modules, representing potential dispersants. Mortality of boll weevils caged on the top surface of a module was 95-100\% after 1- $4 \mathrm{~d}$ when maximum air temperatures were $\geq 33^{\circ} \mathrm{C}$ and $72-100 \%$ when minimum temperatures were $-7^{\circ} \mathrm{C}$ or lower, but a few survived even after experiencing a minimum daily temperature of $-12^{\circ} \mathrm{C}$. Under warm (daily maximum temperatures $\geq 25^{\circ} \mathrm{C}$ ) and cold (daily minimum temperatures $\leq 0^{\circ} \mathrm{C}$ ) weather conditions, survival was higher under the tarp than on the open surface of the module ( 20 versus $7 \%$ and 42 versus $26 \%$, respectively), but mortality was $100 \%$ in both locations when temperatures reached $34^{\circ} \mathrm{C}$. Our results indicate that although the threat to an eradication zone posed by boll weevil dispersal from an infested module is very low under most environmental conditions, it is probably greatest when 1) a module is constructed and transported from an infested zone during weather too cool for flight, followed by warm weather favorable for flight at the gin yard; or 2) such a module is transported immediately after construction in moderate-to-warm weather.
\end{abstract}

KEY WORDS Anthonomus grandis, boll weevil eradication, cotton gin, cotton module, dispersal

THE BOLL WEEvIL, Anthonomus grandis grandis Boheman, is being progressively eliminated from U.S. cotton-growing regions by intensive eradication programs that began in the late 1970s (Smith 1998, Dickerson et al. 2001, Grefenstette and El-Lissy 2003). At present, much of the south central portion of the Cotton Belt is still undergoing active boll weevil eradication, with some zones being farther along in the process than others. In Texas and surrounding states, it is common for a zone that is far advanced in boll weevil suppression to share one or more borders with zones that still harbor substantial weevil populations, and the threat of reintroductions from the latter is a

Mention of trade names or commercial products in this article is solely for the purpose of providing specific information and does not imply recommendation or endorsement by the U.S. Department of Agriculture.

${ }^{1}$ Corresponding author, e-mail: tsapping@iastate.edu.

${ }^{2}$ Texas Agricultural Experiment Station, Texas A\&M University, Lubbock, TX 79403.

${ }^{3}$ USDA-ARS-CPPRU, Lubbock, TX 79403.

${ }^{4}$ Texas Cooperative Extension, Texas A\&M University, Dallas, TX 75252 .

${ }^{5}$ Texas Cooperative Extension, Texas A\&M University, Weslaco, TX 78596 . major concern (Adamczyk and Burris 2004, Allen et al. 2005, Kiser and Catanach 2005). Specifically, there has been apprehension over the potential for cotton gins located in advanced eradication zones to serve as sites of boll weevil introductions when processing cotton harvested by customers in neighboring infested zones. Ginning of infested cotton contributed to the initial spread of the boll weevil through the Cotton Belt a century ago (Hunter 1904).

Cotton modules are large $(\approx 6,800-\mathrm{kg})$ free-standing stacks of harvested seed cotton that are constructed with a module builder in the field by the grower, covered with a plastic tarp, and later picked up by a module truck for transport to the gin (Lalor et al. 1994). Modules can vary in height (commonly $2.7 \mathrm{~m}$ ), but they have a standard width of $2.45 \mathrm{~m}$ and standard length of $9.75 \mathrm{~m}$. Surveys in three infested regions of Texas in 2001-2002 revealed that boll weevils are likely to be harvested with the cotton, packed into cotton modules, and fed alive into the gin plant (Sappington et al. 2004d). Extensive ginning experiments have indicated that a boll weevil entering the gin plant in seed cotton has an extremely low probability of escaping alive (Brashears et al. 2002; Hughs et al. 2002; Sap- 
pington et al. 2004a, b, c). However, reintroductions to an eradication zone might occur before boll weevils ever enter the gin if they disperse from the surface of a module on route to the gin yard or after arrival. A proportion of the total boll weevils picked up by the harvester are predicted to occur by chance on or near the surface of a module after its construction. Data from our previous survey suggested that five to 100 boll weevils were packed within $1 \mathrm{~cm}$ of the surface of the cotton modules constructed in the infested fields examined (Sappington et al. 2004d). These represent potential dispersants at the site of construction, during transport to the gin, or after deposit of the module at the gin yard. In this study, we conducted mark-recapture experiments with feral boll weevils to characterize their propensity to disperse from the surface of a module before and during transport. We also examined the mortality to be expected among boll weevils trapped beneath a module tarp on the top surface of a module under a wide range of ambient temperatures.

\section{Materials and Methods}

Dispersal from Stationary Modules. Experiments were conducted in the subtropical Lower Rio Grande Valley of Texas near Weslaco and in the Northern Blacklands region of Texas near Waxahachie during the cotton harvests in 2001 and 2002 to examine the fate of boll weevils released on various surfaces of stationary cotton modules. Neither of these regions was participating in a boll weevil eradication program during those years. In Weslaco in 2001, we used modules located in the grower's field at the point where they were constructed and where they awaited pick-up by a module truck from a local gin. These modules were $\approx 0-2 \mathrm{~d}$ old. In Waxahachie in 2001, and in both locations in 2002, our experiments were conducted in gin yards by using modules $0-7$ d old awaiting their turn to be ginned. We switched to working in the gin yards because the availability of modules for our experiments over one or more days was more predictable.

Boll weevils to be used in mark-recapture experiments were captured locally the day before release in Hercon Scout boll weevil pheromone traps (Hercon Environmental, Emigsville, PA) baited with a 10-mg Hercon aggregation pheromone lure and were held in cages overnight in the laboratory at $22^{\circ} \mathrm{C}$. Traps were serviced daily to ensure that boll weevils were as vigorous and healthy as possible. Groups of 25 boll weevils of mixed sexes were marked with enamel paint or fluorescent powder (Switzer Brothers, Cleveland, $\mathrm{OH})$. They were released onto the surface of modules within a $0.5-\mathrm{m}$-diameter circular release zone marked with module paint at each of five locations per module. Three releases were made on the top of each module by dumping all 25 weevils into the center of each zone and immediately covering them with the module tarp. Module tarps are synthetic coverings that completely cover the top and extend about one-third of the way down the sides to protect the module from rain (Lalor et al. 1994, Willcutt and McCarty 2000, Shaw 2002). Two more releases were made, one on each of the long sides of the module free of the tarp, by placing weevils individually on the surface by hand while making sure none fell. Each release zone represented a replication. Releases were typically made on three to four modules per day over a 3- to 4 -d period at each location. The total number of releases per year and geographic location ranged from 16 to 24 on the sides and from 21 to 36 on the tops depending on the number of boll weevils available and other logistical constraints.

Boll weevils remaining in or near (within $30 \mathrm{~cm}$ ) the release zones were recovered after $\approx 24 \mathrm{~h}$ and were classified as dead or alive. Moribund weevils were considered alive. An exception was in Waxahachie in 2001 in which weevils marked with fluorescent powder were recovered at night $\approx 10 \mathrm{~h}$ after release with the aid of hand-held blacklight lamps. We thought this method might improve our ability to recover released weevils compared with searching for them in daylight, but we concluded that it did not. Boll weevils feign death when disturbed, so we tested each apparently dead weevil by pinching the base of the snout and watching for movement. In addition, weevils remaining on the module sides were counted 10 min after release, because many were observed to disperse by flight soon after placement. For each set of releases except Weslaco in 2001, 25 marked boll weevils were placed in a closed, white cardboard 0.25-liter carton, which was placed on the ground at the base of each module in an area receiving the most shade throughout the day. These weevils served as controls for baseline mortality.

Dispersal from Modules during Transport. In October 2001, an experiment was conducted at the USDA-ARS Cotton Ginning Research Laboratory in Lubbock, TX, to determine whether boll weevils were more prone to disperse from modules transported a long distance $(48 \mathrm{~km})$ than a short distance $(10 \mathrm{~km})$, representing the typical range covered during transfer from the field to a gin. The longer trip took 35-40 min to complete, whereas the shorter trip took 10-12 min to complete. Two modules were used in this study and had been constructed $\approx 1$ mo earlier and saved by Ginning Lab personnel for use in various future experiments, including this experiment. Three sets of 25 weevils marked with fluorescent powder were released per module into 0.5-m-diameter zones marked with module paint: one on top, one on a long side, and one on the end that faced out of the open back of the module truck. The weevils were collected in pheromone traps as described previously, except they were sometimes held for up to $4 \mathrm{~d}$ in a cage with water in the laboratory before use. Because it was impossible to release weevils on the top and side of the module after being loaded in the truck, all were released just before the module was loaded. The time it took to release the weevils and the time necessary for loading itself, meant that modules were loaded into the truck within 15 min of the first marked boll weevils being released. As in the stationary module experiment described above, some weevils dispersed soon after placement. 
Although the magnitude of early dispersal was much less in this experiment than the previous experiment because of lower ambient temperatures (this experiment was conducted in October; the others in August and September), we did not try to count them, because that would have delayed loading even further. In effect, our method imitates the worst-case situation of taking a module out of the field as soon as it is constructed, thus minimizing (but not eliminating) the opportunity for dispersal from the module before transport. This process would almost never take $<15$ min in the field.

After return from a round-trip of the treatment distance, the module was unloaded from the truck onto a pallet, loaded onto a trailer, and pulled into a dark shed to be inspected for marked weevils with the aid of hand-held blacklight lamps. If some weevils were not present in the release zone, a further search was conducted out to $1 \mathrm{~m}$ beyond the zone. Cotton on the sides of a module is tightly packed and difficult for a boll weevil to penetrate, but on the module top it is much looser. Therefore, cotton within the release circle on the top of the module was searched to a depth of $\approx 20 \mathrm{~cm}$ for boll weevils that may have burrowed downward. Ambient air temperatures at the time of each release were obtained from a CR10 weather station (Campbell Scientific, Logan, UT) located at the experimental site.

To control for time of day and temperature effects, transport distance treatments were performed in pairs, each pair representing a trial. Five trials were conducted. Recovery data after transport included the sum of weevils found on the surface and those that had burrowed. Proportion recovery data were arcsine square-root transformed before analyses (Fry 1993), but untransformed means of percentage of recovery are presented. Effect of location of boll weevils on the module was tested by analysis of variance (ANOVA) with transformed proportion recovery as the dependent variable and release location and distance transported as main effects. Trial was a blocking factor, which accounted for variability caused by different ambient temperatures at the time of each paired transport event. Significant differences between release locations were identified by Tukey's honestly significant difference (HSD) method $(\alpha=0.05)$ (Keppel 1973). Linear regression was used to reveal the relationship between ambient temperature (independent variable) and percentage of recovery (dependent variable) from each of the release site locations on the module after transport. A suspected outlier for percentage of recovery from the top of a module was tested according to the procedure of Cook (1977). All statistical analyses were performed using Statistix7 software (Analytical Software 2000), except the twofactor ANOVA, which was performed using SAS 8.02 software (SAS Institute 2000).

Temperature and Survival on a Tarped or Untarped Surface. A study was conducted at the USDA-ARS Cotton Ginning Research Laboratory at Lubbock, TX, to quantify survival of boll weevils on the top of a cotton module in relation to temperature when cov- ered or not covered with a tarp. A cotton module was placed in an unshaded location with the long axis running east-west, and the same module was used throughout the experiment which lasted $14 \mathrm{mo}$. Tarped and untarped treatment areas were established on the top surface of the module. One-half of the surface was covered with a medium-blue plastic module tarp, and the other half with $>1$-mm-diameter plastic mesh of a $2.54-$ by $2.54-\mathrm{cm}$ weave. Two locations were tested in each treatment area, one near the end and the other near the center of the module to more accurately characterize the tarped and untarped microenvironments.

Twenty-five live boll weevils, obtained from the laboratory colony maintained at the USDA-APHIS Mission Plant Protection Center in Mission, TX, were placed into each of 1610 - by 5 -cm cylindrical aluminum screen cages containing $\approx 10 \mathrm{~g}$ of seed cotton. On 43 occasions the supply of weevils was insufficient to place 25 weevils per cage, but there were never fewer than 23 in any cage. Four cages holding test weevils were placed at each of the four test locations on the module. One cage was removed from each of the four locations at 1,2,3, and $4 \mathrm{~d}$ after placement (DAP). The weevils were examined for mortality by placing them on a heat table and watching for movement. Data for the two locations within each treatment were pooled for all analyses (resulting in cohorts of 50 weevils per treatment). This procedure was conducted 64 times, beginning in September 2001 and ending in October 2002. Data collected in September 2001 and September 2002 were pooled, and data collected in October 2001 and October 2002 were pooled. In total, 25,147 boll weevils were tested in the experiment.

A CR-10 (Campbell Scientific) micrologger was installed next to the module and temperature probes were placed at each of the four locations on top of the module. A probe also was installed inside a sun shield attached to the weather station to record air temperature. Temperatures were recorded for the duration of the test, and the relationships between tarped and untarped module surface temperatures and ambient temperature were analyzed with linear regression using Statistix7 software (Analytical Software 2000). Boll weevil mortality under the module tarp versus mortality in the open area on top of the module was compared by month by using a paired $t$-test, and separately for warm (highest daily maximum during exposure period $\geq 25^{\circ} \mathrm{C}$ ) and cold (lowest daily minimum during exposure period $\leq 0^{\circ} \mathrm{C}$ ) temperature groupings using the Wilcoxon matched pairs signed rank test (Daniel 1990, Analytical Software 2000). Percentage of mortality within these groupings was regressed on highest daily maximum or lowest daily minimum temperature during each exposure period, excluding data points after mortality plateaued at $100 \%$. Differences in tarped and untarped patterns of mortality were examined by comparing the slopes and elevations of these regression lines, as performed by Statistix7 software (Analytical Software 2000). 
Table 1. Mean $\pm \mathrm{SE}$ fate of marked boll weevils $10 \mathrm{~min}$ and $10 \mathrm{~h}$ (Wax 2001 only) or $24 \mathrm{~h}$ after release (25 weevils per release) on side surfaces of cotton modules

\begin{tabular}{|c|c|c|c|c|c|c|c|}
\hline \multirow{2}{*}{ Yr } & \multirow{2}{*}{ Location } & \multirow{2}{*}{ Release date } & \multirow{2}{*}{ No. releases } & \multirow{2}{*}{$\begin{array}{l}\% \text { dispersed } \\
\text { by } 10 \mathrm{~min}\end{array}$} & \multicolumn{2}{|c|}{ Recovered at $10-24 \mathrm{~h}$} & \multirow{2}{*}{$\begin{array}{l}\% \text { dispersed } \\
\text { by } 10-24 \mathrm{~h}\end{array}$} \\
\hline & & & & & $\%$ alive/release & $\%$ dead $/$ release & \\
\hline \multirow[t]{2}{*}{2001} & Wes & 6-9 Aug. & 16 & $87.2 \pm 2.93$ & $1.2 \pm 0.60$ & $1.6 \pm 0.60$ & $97.1 \pm 0.92$ \\
\hline & Wax & 21-24 Sept. & 24 & $87.0 \pm 5.84$ & $2.0 \pm 1.36$ & $4.4 \pm 1.52$ & $93.7 \pm 2.14$ \\
\hline \multirow[t]{2}{*}{2002} & Wes & 12-15 Aug. & 24 & $56.2 \pm 5.54$ & $2.4 \pm 0.72$ & $1.2 \pm 0.64$ & $96.3 \pm 0.99$ \\
\hline & Wax & 16-17 Sept. & 24 & $82.2 \pm 2.41$ & $1.2 \pm 0.44$ & $3.6 \pm 0.92$ & $95.3 \pm 1.17$ \\
\hline
\end{tabular}

Wax, Waxahachie; Wes, Weslaco.

Table 2. Mean $\pm \mathrm{SE}$ recovery of marked boll weevils at $10 \mathrm{~h}$ (Wax 2001 only) or $24 \mathrm{~h}$ after release (25 weevils per release) on top of cotton modules covered with tarp immediately after weevils were released

\begin{tabular}{|c|c|c|c|c|c|c|c|}
\hline \multirow{2}{*}{$\mathrm{Yr}$} & \multirow{2}{*}{ Location } & \multirow{2}{*}{ Release date } & \multirow{2}{*}{ No. releases } & \multicolumn{3}{|c|}{ Recovered (or missing) at $10-24 \mathrm{~h}$} & \multirow{2}{*}{$\begin{array}{l}\% \text { controls alive } \\
\text { at } 10-24 \mathrm{~h}\end{array}$} \\
\hline & & & & $\%$ alive/release & $\%$ dead/release & $\%$ missing/release & \\
\hline \multirow[t]{2}{*}{2001} & Wes & 6-9 Aug. & 21 & $0.8 \pm 0.44$ & $52.8 \pm 2.84$ & $46.4 \pm 2.76$ & \\
\hline & Wax & 21-24 Sept. & 30 & $0.8 \pm 0.32$ & $28.0 \pm 4.08$ & $71.2 \pm 4.20$ & $92.4 \pm 3.08$ \\
\hline \multirow[t]{2}{*}{2002} & Wes & 12-15 Aug. & 34 & $1.6 \pm 1.20$ & $90.4 \pm 2.84$ & $8.0 \pm 2.48$ & $93.6 \pm 1.80$ \\
\hline & Wax & 16-17 Sept. & 36 & $4.8 \pm 1.00$ & $59.2 \pm 3.72$ & $36.0 \pm 3.72$ & $86.0 \pm 5.12$ \\
\hline
\end{tabular}

Wax, Waxahachie; Wes, Weslaco.

\section{Results}

Dispersal from Stationary Modules. Very few boll weevils released on the sides of modules were still present after $24 \mathrm{~h}$, whether dead or alive (Table 1). Generally, the majority of weevils dispersed from the module sides within 10 min after release. An exception was a series of releases on the morning of 24 September 2001 in Waxahachie when temperature was $<18^{\circ} \mathrm{C}$; none of the weevils flew during the first $10 \mathrm{~min}$. Another exception (15 August 2002, Weslaco) occurred during releases on a morning after a nighttime rain, where only $\approx 20 \%$ of the weevils dispersed during the first $10 \mathrm{~min}$. Although it was sunny and air temperature at the time of release on this date was $>27^{\circ} \mathrm{C}$, evaporative cooling of the module surface may have influenced boll weevil behavior. Nevertheless, 90 and $94 \%$ of the released weevils on both of these dates, respectively, had dispersed by $24 \mathrm{~h}$.

Dispersal was primarily by flight, but a small number of weevils were observed to walk upward from the release circle and into the shade afforded by the tarp by $10 \mathrm{~min}$ after release. Boll weevils generally had little difficulty walking on the sides of the modules, although some occasionally became tangled in the fibers. Among the few live and dead boll weevils still present after $24 \mathrm{~h}$ (Table 1), about one-half were obviously tangled in the cotton fibers, and some were moribund. Occasionally, an untangled, apparently healthy live weevil was observed.

Most boll weevils recovered on the top surface of the module under the tarp were dead (Table 2), presumably from high temperatures. In contrast, mortality of control weevils exposed only to ambient temperature on the most shaded side of the modules was low (Table 2). Most of the weevils that could not be found after $24 \mathrm{~h}$ probably burrowed into the loose cotton on the top of the module, and some perhaps escaped lethal temperatures in this way. Direct evidence for burrowing was found in the transport experiment and is discussed below. Boll weevils had great difficulty walking across the loosely packed cotton on the top surfaces of modules without becoming tangled, and it seems unlikely that any could have walked from their release sites under the tarp to the sides of the module and out from under the tarp to disperse by flight. We found very few weevils outside the release circles, and most were recovered within a few centimeters of the center of the circle where they were released, often tangled in cotton fibers.

Dispersal from Modules during Transport. Overall recovery of marked boll weevils after transport 10 or $48 \mathrm{~km}$ (Table 3) was considerably higher than in the stationary module experiment, because the transport experiment was conducted in late October when lower overall temperatures (Fig. 1) did not promote dispersal. This experiment reflected a worst-case scenario in which a module is loaded for transport im-

Table 3. Mean $\pm \mathrm{SE}$ percentage of recovery of marked boll weevils released on the end, side, and top of a cotton module transported 10 or 48 km, Lubbock, TX, October 2001

\begin{tabular}{|c|c|c|c|}
\hline \multirow{2}{*}{ Release location } & \multicolumn{3}{|c|}{ Transport distance } \\
\hline & $10 \mathrm{~km}$ & $48 \mathrm{~km}$ & Pooled $^{a}$ \\
\hline End & $33.6 \pm 16.13$ & $48.3 \pm 9.46$ & $41.0 \pm 9.15 \mathrm{a}$ \\
\hline Side & $45.8 \pm 14.89$ & $52.0 \pm 19.47$ & $48.9 \pm 11.60 \mathrm{a}$ \\
\hline Top (total) & $78.4 \pm 12.94$ & $91.2 \pm 7.84$ & $84.8 \pm 7.44 b$ \\
\hline Top (burrowed) ${ }^{b}$ & $3.2 \pm 2.33$ & $5.6 \pm 3.49$ & $4.4 \pm 2.02$ \\
\hline
\end{tabular}

In this experiment, all recovered boll weevils were still alive.

${ }^{a}$ Distance did not significantly affect percent recovery $\left(F_{1,15}=\right.$ $3.98 ; P=0.065)$, so results for release location were pooled. The effect of release location on recovery was significant $\left(F_{2,15}=15.09 ; P=\right.$ $0.0003)$; means followed by the same letter were not significantly different (Tukey HSD, $\alpha=0.05$ ).

${ }^{b}$ Recovered between 2.5 and $20 \mathrm{~cm}$ below the top surface. 

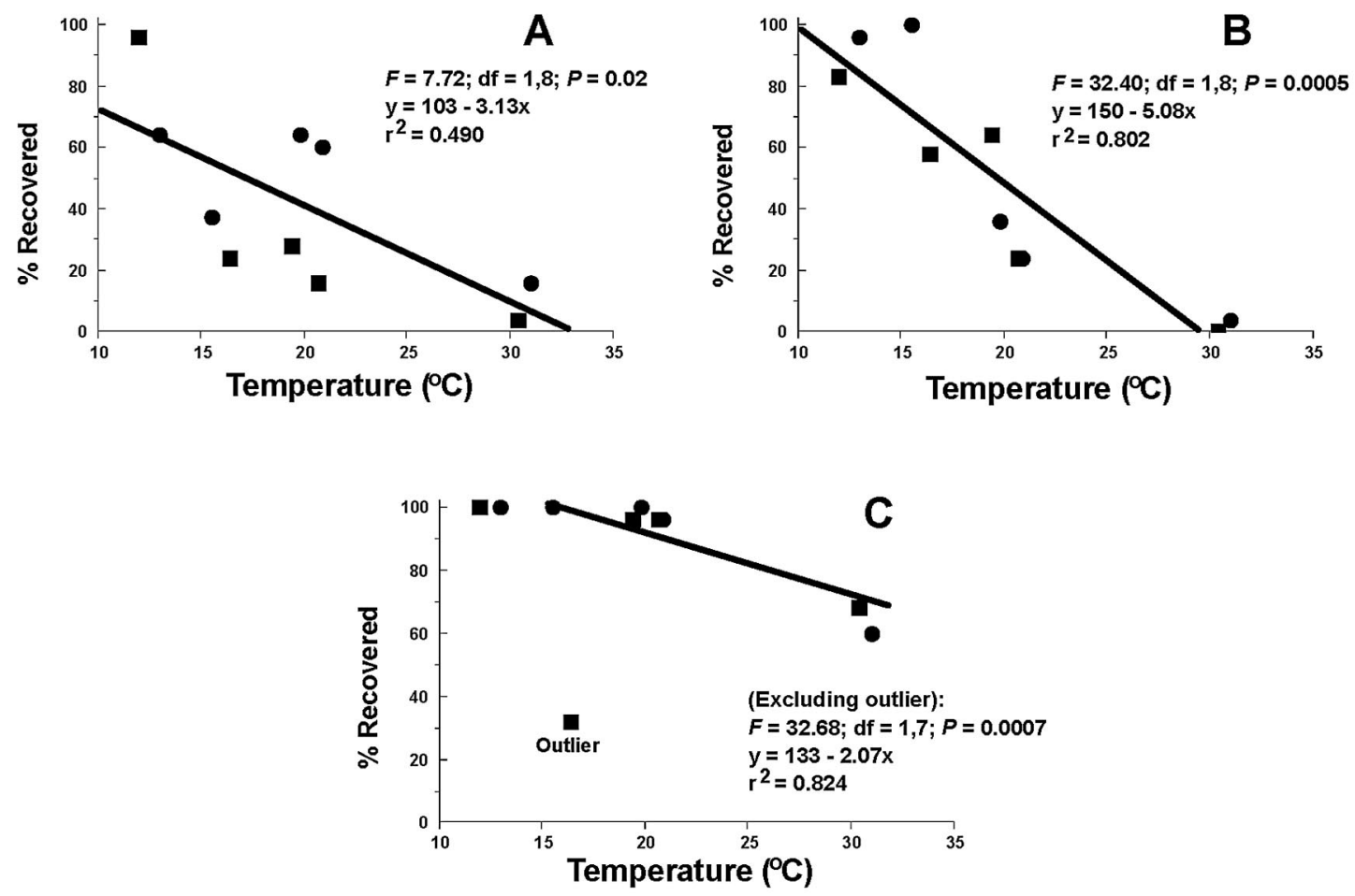

Fig. 1. Linear regressions of percentage of recovery of marked boll weevils from release sites on ambient temperature after transport of 10 or $48 \mathrm{~km}$, Lubbock, TX, 2001. Twenty-five boll weevils each were released on (A) the end of the module facing out of the module truck, (B) one side of the module, and (C) the top of the module (covered by a tarp).

mediately (within $15 \mathrm{~min}$ ) after construction in cool weather, minimizing the opportunity for boll weevil dispersal from the module before transport into an eradication zone. An ANOVA of percentage of recovery of released boll weevils after transport (Table 3) indicated that the overall two-factor model was significant $\left(F_{14,15}=5.79 ; P=0.0008\right)$, with trial accounting for a significant amount of variation $\left(F_{9,15}=5.19\right.$; $P=0.0026)$, as expected because of the different ambient temperatures among the trials. There was no significant interaction between release location on the module and distance transported $\left(F_{2,15}=0.09 ; P=\right.$ $0.92)$. Distance did not significantly affect percentage of recovery $\left(F_{1,15}=3.98 ; P=0.065\right)$. The effect of release location on recovery was significant $\left(F_{2,15}=\right.$ 15.09; $P=0.0003$ ), with recovery on the top of the module being significantly higher than that on the side or on the end (Table 3). All boll weevils recovered in this experiment were still alive.

Percentage of recovery at each release location on the module decreased with increasing temperature (Fig. 1). There was no significant difference in the slopes $(F=1.83 ; \mathrm{df}=1,16 ; P=0.20)$ of the regression lines for end and side release locations (Fig. 1A, B). The data point for percentage of recovery on the top of the module transported $10 \mathrm{~km}$ at $\approx 16^{\circ} \mathrm{C}$ (Fig. 1C) was determined to be an outlier $(t=-9.01, P=$ 0.00004 ) and was excluded from all analyses. The slope of the regression for recovery on the top, excluding the outlier, was flatter than those of the end and side, reflecting the difficulty of weevils dispersing from under the tarp, but the difference was not significant when tested against pooled end and side data $(F=$ 3.35 ; df $=1,25 ; P=0.08)$.

The percentage of recovery of boll weevils on the top of the module that had burrowed $\geq 2.5 \mathrm{~cm}$ into the cotton increased as temperature increased (Fig. 2). Cotton on the top surface of the module is not packed as tightly as it is on the sides, and a weevil could easily walk downward into it, at least until it became tangled

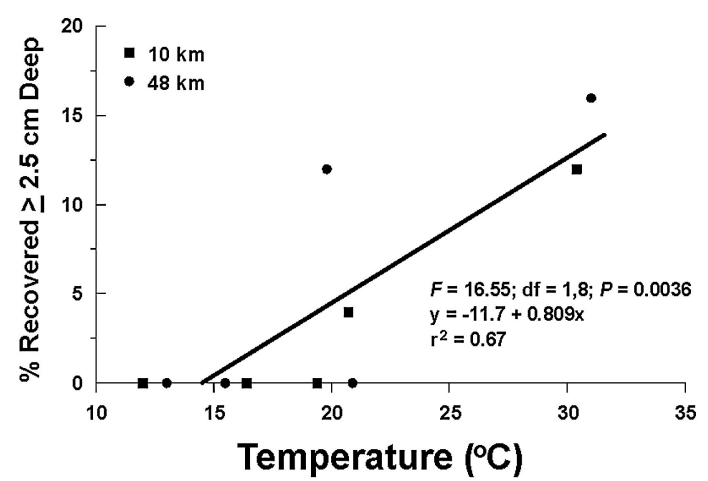

Fig. 2. Linear regression of the percentage of marked boll weevils recovered $\geq 2.5 \mathrm{~cm}$ deep in the release zone on top of the cotton module after transport of 10 or $48 \mathrm{~km}$ in a module truck, Lubbock, TX, 2001. 
Table 4. Estimated parameters from linear regression of temperature at the top surface of a cotton module, both under a blue module tarp and in an untarped open area, on ambient air temperature, Lubbock, TX, September 2001-October 2002

\begin{tabular}{clcccc}
\hline \hline $\mathrm{Y}$ & Test area & Intercept & Slope & Slope $P>t$ & $r^{2}$ \\
\hline \multirow{2}{*}{ Max temp } & Tarped & 2.89 & 1.94 & $<0.0001$ & 0.858 \\
& Untarped & 4.94 & 1.14 & $<0.0001$ & 0.797 \\
\multirow{2}{*}{ Min temp } & Tarped & -1.19 & 1.74 & $<0.0001$ & 0.928 \\
& Untarped & -0.67 & 1.12 & $<0.0001$ & 0.953 \\
\hline
\end{tabular}

in the fibers. One marked weevil was recovered $20 \mathrm{~cm}$ down into the cotton in the release zone.

Temperature and Survival on a Tarped or Untarped Surface. Temperature. Observation of plots of daily maximum and minimum air temperatures versus respective module temperatures indicated that a linear model would best fit the data of both tarped and untarped areas. Maximum and minimum temperatures at the module surface in both the tarped and untarped areas were moderately to highly correlated with air maximum and minimum temperatures, respectively, with $r^{2}$ values ranging from 0.797 to 0.953 (Table 4).
Slopes of all four models were significantly greater than zero $(P<0.0001)$, and all were greater than 1 . Sunlight absorbed by the tarps and radiated downward as heat raised the temperature of the module surface under the tarp considerably above ambient air temperature. Slopes of 1.94 and 1.74 for maximum and minimum temperature models, respectively, indicate that temperatures under the tarp were nearly double that of air temperature. In contrast, the slopes for the untarped area were only slightly $>1$ (Table 4 ), indicating a close tracking of air temperature at the exposed upper surface of the module.

Survival. After 1, 2, 3, and 4 DAP, no boll weevils survived under the module tarp when the highest daily maximum air temperature during that period was $\geq 36$, 34,34 , and $33^{\circ} \mathrm{C}$, respectively (Fig. 3), or in the untarped area when the highest daily maximum air temperature was $\geq 34,33,33$, and $33^{\circ} \mathrm{C}$, respectively (Fig. 4). Slopes of regression lines for tarped and untarped percentage of mortality on temperature did not differ significantly at any DAP (Figs. 3 and 4). Elevation of the lines differed for the warm temperature grouping at 3 and $4 \mathrm{DAP}$, indicating that mortality at lower
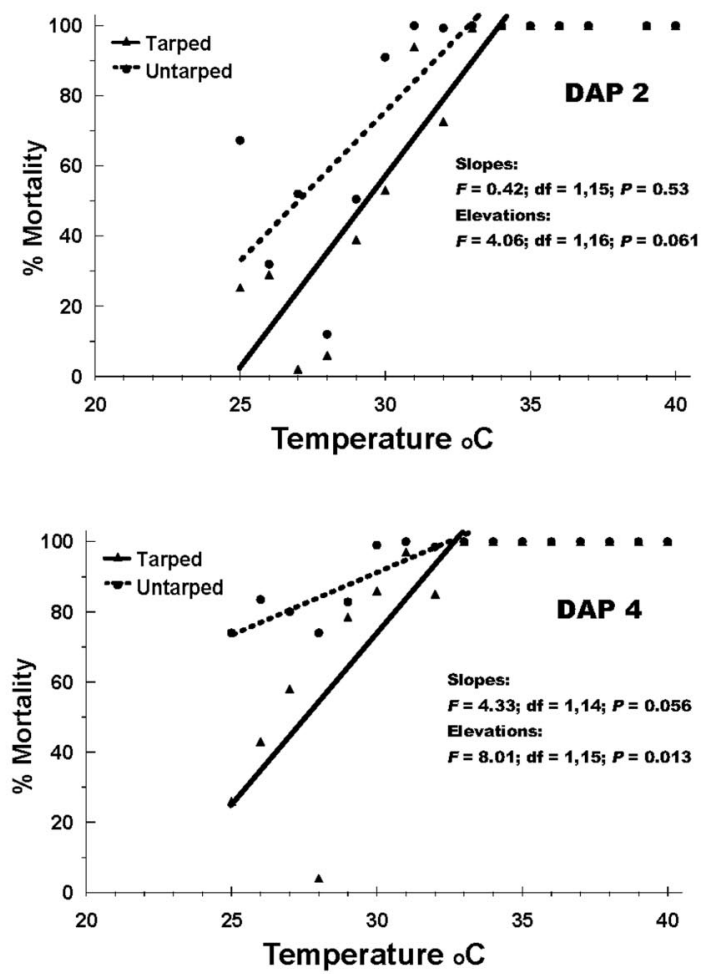

Fig. 3. Relationship between percentage of mortality of boll weevils held in cages on tarped or untarped upper surface of a cotton module to highest maximum daily temperature experienced during exposure period at $1,2,3$, or 4 DAP. Lines are regressions through data points including the first $100 \%$ mortality point at the beginning of the $100 \%$ mortality plateau. Results of comparisons of slopes and elevations of tarped and untarped regression lines are indicated. Regression equations: tarped, DAP 1: $y=-189+8.26 x ; F_{1,9}=16.92 ; P=0.0026 ; r^{2}=0.65$ and untarped, DAP $1: y=-229+10.05 x ; F_{1,7}=13.45$; $P=0.0080 ; r^{2}=0.66$. Tarped, DAP $2: y=-269+10.88 x ; F_{1,8}=26.18 ; P=0.0009 ; r^{2}=0.77$ and untarped, DAP $2: y=-178$ $+8.46 x ; F_{1,7}=7.08 ; P=0.032 ; r^{2}=0.50$. Tarped, DAP $3: y=-195+8.75 x ; F_{1,8}=11.64 ; P=0.0092 ; r^{2}=0.59$ and untarped, DAP 3: $y=-53+4.26 x ; F_{1,8}=22.68 ; P=0.0014 ; r^{2}=0.72$. Tarped, DAP $4: y=-217+9.70 x ; F_{1,7}=11.65 ; P=0.011 ; r^{2}=$ 0.63 and untarped, DAP $4: y=-15+3.57 x ; F_{1,7}=20.61 ; P=0.0027 ; r^{2}=0.75$. 

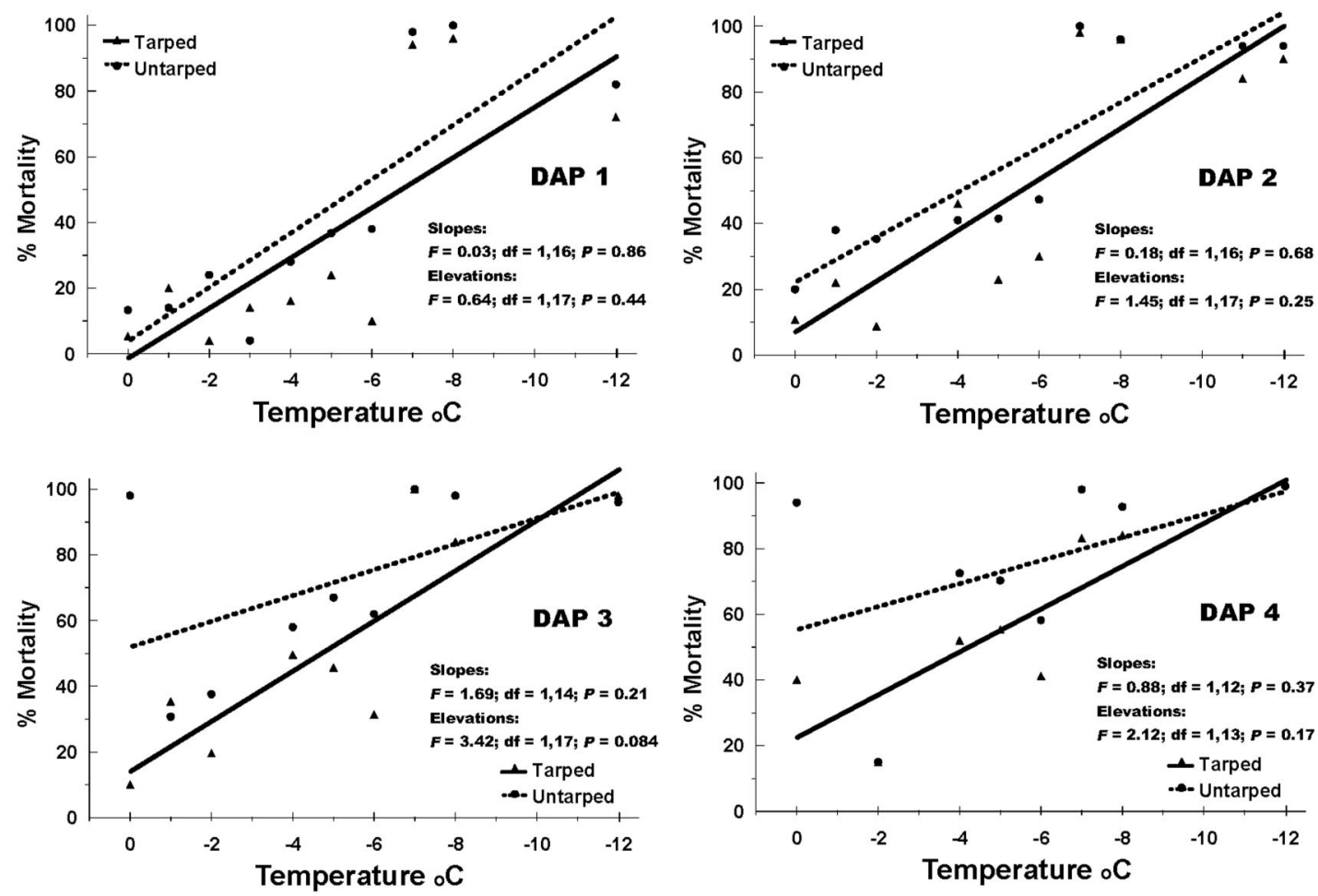

Fig. 4. Relationship between percentage of mortality of boll weevils held in cages on tarped or untarped upper surface of a cotton module to lowest minimum daily temperature experienced during exposure period at $1,2,3$, or 4 DAP. Note that temperature values on the $x$-axis are presented in descending order. Results of comparisons of slopes and elevations of tarped and untarped regression lines are indicated. Regression equations: tarped, DAP 1: $y=-1.15-7.64 x ; F_{1,8}=10.33 ; P=0.0012$; $r^{2}=0.56$ and untarped DAP $1: y=4.41-8.21 x ; F_{1,8}=16.84 ; P=0.0034 ; r^{2}=0.68$. Tarped, DAP $2: y=7.64-7.71 x ; F_{1,8}=$ 19.17; $P=0.0024 ; r^{2}=0.71$ and untarped, DAP $2: y=22.7-6.79 x ; F_{1,8}=26.86 ; P=0.0008 ; r^{2}=0.77$. Tarped, DAP 3: $y=$ $14.46-7.63 x ; F_{1,7}=19.58 ; P=0.0031 ; r^{2}=0.74$ and untarped, DAP $3: y=52.4-3.90 x ; F_{1,7}=2.89 ; P=0.13 ; r^{2}=0.29$. Tarped, DAP 4: $y=22.9-6.53 x ; F_{1,6}=16.76 ; P=0.0064 ; r^{2}=0.74$ and untarped, DAP $4: y=55.6-3.52 x ; F_{1,6}=1.59 ; P=0.25 ; r^{2}=$ 0.21 .

temperatures (e.g., $25^{\circ} \mathrm{C}$ ) was higher in the untarped area than the tarped area (Fig. 4). Average maximum air temperature during the hot months (June-August) was $>33^{\circ} \mathrm{C}$, and in all cases weevils suffered $100 \%$ mortality by 4 DAP in both the tarped and untarped areas (Fig. 5). During test periods with moderate air temperatures $\left(-6\right.$ to $\left.26^{\circ} \mathrm{C}\right)$, weevil mortality was low even after 4 DAP (Figs. 3 and 4), being $0 \%$ in some individual test periods (data not shown) and averaging as low as $15.5 \%$ for December (Fig. 5). Mortality was high $(93.3 \% \pm 1.4)$ during periods when the lowest minimum air temperature was $-7^{\circ} \mathrm{C}$ or lower but reached $100 \%$ after 4 DAP in the tarped area only after experiencing a minimum temperature of $-12^{\circ} \mathrm{C}$, the lowest temperature recorded in the study (Fig. 4). During the cold months (November-February), the highest mean monthly mortality by 4 DAP was 72 and $74 \%$ in the tarped and untarped areas, respectively (Fig. 5).

Paired $t$-tests within months indicated that mortality between tarped and untarped areas (Fig. 5) was significant $(P<0.05)$ only in October. However, Wil-

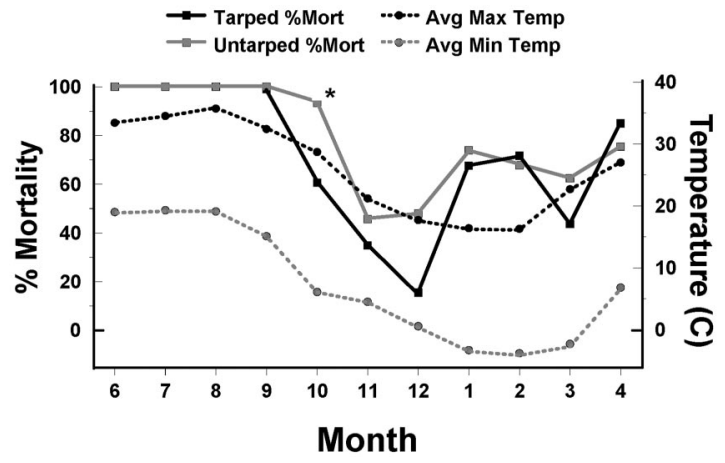

Fig. 5. Mean percentage of mortality of caged boll weevils on the top surface of a cotton module after four days of exposure, either covered by a module tarp or not, along with mean maximum and minimum air temperatures, by month, Lubbock, TX, September 2001-October 2002. Data were not collected in May 2002. Data for overlapping months, i.e., September and October, were pooled by month. *, mortality between tarped and untarped areas within a month was significantly different according to paired comparison $t$-tests $(\alpha=0.05)$. 
coxon matched pairs signed rank tests (Daniel 1990, Analytical Software 2000) of mean percentage of boll weevil mortality at warm temperatures (highest daily maximum $\geq 25^{\circ} \mathrm{C}$ ) (Table 4 ) indicated that it was consistently less in the tarped than untarped area at 1 DAP (normal approximation of 2.03, $P=0.042$ ), 2 DAP (normal approximation of 2.61, $P=0.009$ ), 3 DAP (normal approximation of $2.45, P=0.014$ ), and 4 DAP (normal approximation of $2.45, P=0.014$ ). At cold temperatures (lowest daily minimum $\leq 0^{\circ} \mathrm{C}$ ), the difference in mortality between the tarped and untarped areas was not significant at 1 DAP (normal approximation of $1.89, P=0.059$ ) but was significantly less in the tarped area at 2 DAP (normal approximation of $2.25, P=0.024$ ) , 3 DAP (normal approximation of 2.03, $P=0.042$ ), and 4 DAP (normal approximation of 2.11, $P=0.035)$.

\section{Discussion}

The interval between cotton module construction and transport to the gin yard as well as how long the module rests in the gin yard before being ginned depends on how busy the gin is at that time. During peak harvest, it is common for modules to remain in the field for 1 to $2 \mathrm{~d}$ and in the gin yard for up to a week. Sappington et al. (2004d) found that live boll weevils are packed alive into cotton modules, sometimes in large numbers. Those packed on or near the surface can be considered potential dispersants. Those that disperse from the module before its removal from the field are not an issue, but those that remain on the module long enough to be loaded into the transport truck represent a potential hazard to any eradication zone into which they enter. In this study, we found that all boll weevils caged on the untarped upper surface of a module were dead after $4 \mathrm{~d}$ during all test periods in June-September, and mortality was very high $(\geq 92 \%)$ after only $24 \mathrm{~h}$ on days with a maximum temperature $\geq 31^{\circ} \mathrm{C}$. The behavior of the released boll weevils in this study likewise indicates that the exposed surface of a cotton module is a hostile environment and that most weevils disperse from it as soon as possible after module construction.

However, our data suggest it was difficult or impossible for boll weevils to escape from under the tarp, which the grower places over the top of the module to protect it from the elements while awaiting ginning. If the insects can survive under the tarp, they might disperse at the gin yard during the few moments that elapse between tarp removal and the module entering the gin plant. Maximum temperatures at the surface of a module under the tarp increased almost $2^{\circ} \mathrm{C}$ for every $1^{\circ} \mathrm{C}$ increase in air temperature, indicating that module tarps have a large heat holding capacity. During the mark-recovery experiments on stationary modules, ambient temperatures were generally hot (daily maximum temperature $>30^{\circ} \mathrm{C}$; Fig. 5), and we expected mortality of weevils released under the tarp to be high. It was indeed high, but this may not have been entirely because of temperature per se. The mortality we observed for caged weevils under the tarp was less than that of those on the exposed surface on days of hot, but not extreme, air temperatures. The reason for this finding is unknown, but it may have been because of greater desiccation of weevils in the open area, which also were exposed to wind and direct sunlight. Regardless, survival was low on hot days when boll weevils could not escape the module surface by flight because of being caged or being trapped under a tarp.

We found that some of the boll weevils under the tarp in the module transport experiment burrowed down into the cotton within an hour or less after release, with one weevil reaching a depth of $20 \mathrm{~cm}$. Substantial proportions of the weevils released on the top of the stationary modules were not recovered after $24 \mathrm{~h}$, and although some may have walked out of the release zone and thus escaped detection, it is likely that many of these burrowed into the cotton. The fate of these weevils is unknown, but it seems unlikely that any individuals escaping death by burrowing downward would have time to resurface and disperse after removal of the tarp immediately before ginning, given the observed difficulty the weevils have in moving through fibers with their spiny legs. It is now clear that boll weevils entering the gin plant have a very low probability of survival and escape (Brashears et al. 2002; Hughs et al. 2002; Sappington et al. 2004a, b, c), so temporary avoidance of temperature-induced death by burrowing is not by itself a threat to eradication efforts.

Our results indicate that the probability of boll weevils being transported on the surface of a module to disperse later in an eradication zone, either en route or at the gin yard, is low and decreases rapidly with time after module construction. However, live untangled weevils were occasionally found on the exposed side of a module $24 \mathrm{~h}$ after release, as well as on the top surface under the tarp, and these weevils represent potential dispersants. When temperatures are moderate $\left(-6\right.$ to $\left.26^{\circ} \mathrm{C}\right)$, one-half or more of the weevils trapped under a module tarp can survive for at least $4 \mathrm{~d}$. Even in very cold weather, a minimum temperature as low as $-12^{\circ} \mathrm{C}$ was not enough to kill all boll weevils on the top surface under the tarp, although many of the survivors seemed moribund. A few survivors were recovered up to $3 \mathrm{~d}$ after placement on the untarped surface under such cold conditions. The weevils used in the caged survival study were from a laboratory-reared colony selected for low incidence of diapause. Although mortality because of acute freezing apparently is not related to diapause status (Suh et al. 2002), diapause has been shown to confer an increase in survivability of subfreezing conditions over that of nondiapausing weevils (Slosser et al. 1996). Thus, boll weevils from a natural population, which would contain a higher percentage of diapausing individuals than those tested in this study, might be even more likely than the latter to survive periods of cold temperature. Even though cold weather cannot be relied upon to kill all boll weevils on or near the module surface, sustained cold temperatures will prevent dispersal, and weevils fed into the gin have almost 
no chance of escape (Brashears et al. 2002; Sappington et al. 2004a, b, c).

Together, our results suggest that the greatest threats to an eradication zone, in the context of boll weevil dispersal from a module surface, will occur 1) when a module is constructed and transported from an infested zone during weather too cool for flight, followed by warm weather favorable for flight at the gin yard; or 2) when such a module is transported immediately after construction in moderate to warm weather. Given these considerations, we recommend that if a module from an infested area must wait a day or more before a gin in an advanced eradication zone is prepared to process it, it would be advantageous if it were allowed to remain in the harvested field during the waiting time rather than in the gin yard. Furthermore, immediate transport of a module from an infested to an eradicated zone in moderate-to-warm weather probably poses the highest risk of reintroduction. Any delay in module transport should reduce this risk, and if practical, should be considered.

\section{Acknowledgments}

We thank Latha Bommireddy, Jesus Cabellero, Jr., Manuel Campos, Veronica Cardoza, Art Castro, Jimmy Castro, Andy Cranmer, Valentina Greenberg, Lanthia Jones, Ross Johnson, Anand Sapkota, Ram Babu Shrestha, Bill Turner, and Orlando Zamora for excellent technical assistance; Glen Moore for logistical help in Waxahachie; and Leeda Wood for providing laboratory-reared boll weevils. We thank A. C. Fuller and Marvin Fuller in Progreso and Charlie Spaniel and Tim Harper in Waxahachie for cooperation and the use of modules. Funding was provided in part by grants IPM01-023 to R. Baker and T.W.S. and IPM02-004 to T.W.S. and A.D.B. from the Texas Department of Agriculture and by special moneys from the USDA-ARS.

\section{References Cited}

Adamczyk, J. J., Jr., and E. Burris. 2004. 57th Annual conference report on cotton insect research and control, pp. 1208-1248. In Proceedings of the Beltwide Cotton Conferences, 5-9 January, San Antonio, TX. National Cotton Council, Memphis, TN.

Allen, C. T., L. E. Smith, L. W. Patton, and R. O. Newman. 2005. Texas boll weevil eradication report, pp. 11961205. In Proceedings of the Beltwide Cotton Conferences, 4-7 January, New Orleans, LA. National Cotton Council, Memphis, TN.

Analytical Software. 2000. Statistix for Windows, version 7.0: user's manual. Analytical Software, Tallahassee, FL.

Brashears, A. D., R. V. Baker, T. W. Sappington, S. C. Carroll, M. D. Arnold, and M. N. Parajulee. 2002. Boll weevil survival in baled lint. In Proceedings of the Beltwide Cotton Conferences, 8-12 January, Atlanta, GA. National Cotton Council, Memphis, TN.

Cook, R. D. 1977. Detection of influential observations in linear regression. Technometrics 19: 15-18.

Daniel, W. W. 1990. Applied nonparametric statistics, 2nd ed. PWS-KENT Publishing Company, Boston, MA.

Dickerson, W. A., A. L. Brashear, J. T. Brumley, F. L. Carter, W. J. Grefenstette, and F. A. Harris [eds.] 2001. Boll weevil eradication in the United States through 1999. The Cotton Foundation Publisher, Memphis, TN.
Fry, J. C. 1993. One-way analysis of variance, pp. 3-39. In J. C. Fry [ed.], Biological data analysis: a practical approach. Oxford University Press, Oxford, United Kingdom.

Grefenstette, B., and O. El-Lissy. 2003. Boll weevil eradication update, pp. 131-141. In Proceedings of the Beltwide Cotton Conferences, 6-10 January, Nashville, TN. National Cotton Council, Memphis, TN.

Hughs, S. E., C. B. Armijo, and R. T. Staten. 2002. Boll weevil survival in the ginning system. In Proceedings of the Beltwide Cotton Conferences, 8 -12 January, Atlanta, GA. National Cotton Council, Memphis, TN.

Hunter, W. D. 1904. Controlling the boll weevil in cotton seed and at ginneries. U.S. Department of Agriculture, Farmers' Bull. No. 209.

Keppel, G. 1973. Design and analysis: a researcher's handbook. Prentice-Hall, Inc., Englewood Cliffs, NJ.

Kiser, D., and M. Catanach. 2005. Boll weevil eradication update-Arkansas, 2004, pp. 1074-1090. In Proceedings of the Beltwide Cotton Conferences, 4-7 January, New Orleans, LA. National Cotton Council, Memphis, TN.

Lalor, W. F., M. H. Willcutt, and R. G. Curley. 1994. Seed cotton storage and handling, pp. 16-25. In W. S. Anthony and W. D. Mayfield [eds.], Cotton ginners handbook. U.S. Department of Agriculture, Agricultural Handbook 503.

Sappington, T. W., A. D. Brashears, M. N. Parajulee, S. C. Carroll, M. D. Arnold, and R. V. Baker. 2004a. Boll weevil (Coleoptera: Curculionidae) survival through cotton gin trash fans. J. Econ. Entomol. 97: 1612-1618.

Sappington, T. W., A. D. Brashears, M. N. Parajulee, S. C. Carroll, M. D. Arnold, and R. V. Baker. 2004b. Boll weevil (Coleoptera: Curculionidae) survival through the seed cotton cleaning process in the cotton gin. J. Econ. Entomol. 97: 1323-1329.

Sappington, T. W., A. D. Brashears, M. N. Parajulee, S. C. Carroll, M. D. Arnold, and R. V. Baker. 2004c. Potential for escape of live boll weevils (Coleoptera: Curculionidae) into cottonseed, motes, and cleaned lint at the cotton gin. J. Econ. Entomol. 97: 1773-1781.

Sappington, T. W., A. D. Brashears, M. N. Parajulee, S. C. Carroll, M. D. Arnold, J. W. Norman, Jr., and A. E. Knutson. 2004d. Potential for transport of boll weevils (Coleoptera: Curculionidae) to the cotton gin within cotton modules. J. Econ. Entomol. 97: 934-940.

SAS Institute. 2000. SAS OnlineDoc, version 8. SAS Institute, Cary, NC. (http://v8doc.sas.com/sashtml/).

Shaw, G. 2002. Harvest, pp. 85-92. In Australian dryland cotton, production guide, 3rd ed. Cotton Research \& Development Corporation, Narrabri New South Wales, Australia.

Slosser, J. E., R. Montandon, D. R. Rummel, L. T. Wilson, and T. W. Fuchs. 1996. Survival of diapausing and nondiapausing boll weevils (Coleoptera: Curculionidae) subjected to freezing temperatures. Environ. Entomol. 25: 407-415.

Smith, J. W. 1998. Boll weevil eradication: area-wide pest management. Ann. Entomol. Soc. Am. 91: 239-247.

Suh, P.-C., D. W. Spurgeon, and J. K. Westbrook. 2002. Influence of feeding status and physiological condition on supercooling points of adult boll weevils (Coleoptera: Curculionidae). Environ. Entomol. 31: 754-758.

Willcutt H., and W. H. McCarty. 2000. Seed cotton module storage and handling. Mississippi State University Extension Service Publication 1561.

Received 26 July 2005; accepted 3 October 2005. 